\title{
Sistemas silvopastoriles: una alternativa para resolver el conflicto entre la producción y la conservación del suelo.
}

\author{
Silberman, Juan E. ${ }^{1}$ \\ ${ }^{1}$ Facultad de Agronomía y Agroindustrias - Univ. Nac. de Sgo. del Estero \\ Conferencia dictada en el marco de la XI Reunión Nacional Científico-Técnica de Biología de Suelos. \\ Corrientes (Argentina)- Octubre de 2017
}

El desmonte para agricultura y ganadería involucra la remoción de diferentes tipos de hábitats, incluyendo bosques, sabanas, pastizales y humedales. La Argentina ha sido particularmente afectada por una tasa de deforestación mayor que el promedio continental y mundial. La mayor tasa ocurrió en el norte del país, particularmente en Santiago del Estero, Salta y Chaco. La transformación de los ecosistemas naturales en tierras de cultivo representa una de las mayores amenazas para la biodiversidad global. Estos cambios en el uso del suelo generan efectos importantes a nivel local con consecuencias de escala regional y global, ya que influyen en la biodiversidad, el clima, los ciclos del agua, el carbono y el nitrógeno. Es reconocido que se debe incrementar la producción de alimentos para satisfacer las necesidades de alimentación de una población creciente, produciendo de forma sustentable. Por lo tanto la producción debe capitalizar los procesos biológicos y explotar los recursos sin comprometer el capital natural, como la biodiversidad y los servicios ecosistémicos. De ello se desprende la necesidad de compatibilizar la producción agropecuaria con la conservación de la biodiversidad y la provisión de servicios ecosistémicos. Para ello se propone la implementación de sistemas de producción que imiten la estructura y el funcionamiento de los ecosistemas naturales. En este sentido los sistemas silvopastoriles serían una alternativa que brindaría una solución clave al conflicto entre la expansión de la agricultura y la conservación de los ecosistemas naturales.

Los sistemas silvopastoriles del Chaco implementados sobre bosques secundarios conservan o mejoran el contenido de carbono orgánico del suelo (COS). En los sitios semiáridos son más evidentes las mejoras del COS por efecto de los SP, cuyo incremento se debe a la fracción lábil del carbono.

El contenido de nitrógeno del suelo $(\mathrm{N})$ disminuye un año posterior a la habilitación debido a la demanda de las pasturas introducidas y este balance negativo es más pronunciado en las áreas sin cobertura arbórea. Luego de tres años de la aplicación de RBI, es notable un beneficio de los SSP sobre el contenido de $\mathrm{N}$ del suelo, especialmente en las áreas bajo la cobertura de Ziziphus mistol.

Las comunidades bacterianas del suelo (ARNr 16S) son resilientes al cambio del uso del suelo, es decir que la estructura se altera luego de un año de la transformación y se restaura luego de cinco años. Desde el punto de vista de la funcionalidad de las comunidades microbianas del suelo, las habilidades catabólicas de estos microorganismos y su diversidad funcional son mayores en los sistemas silvopastoriles de 5 años respecto del bosque. Este efecto ha sido atribuido a la composición química de la necromasa de Gatton Panic que ejercería un efecto priming, es decir, que estos compuestos provocan la activación inmediata de la microbiota del suelo.

De acuerdo a estos reportes se podría pensar que los sistemas silvopastoriles son de bajo impacto para la región, comparado transformaciones drásticas como el desmonte total que generan degradación física y química de los suelos del Chaco y detrimento de su biodiversidad. Sin embargo hay evidencias que resaltan que los sistemas silvopastoriles alteran la diversidad de hongos del suelo.

Palabras clave: Biodiversidad, Servicios ecosistémicos, Desmonte, Silvopastoril 